\title{
APLIKASI TEKNIK SWADDLING, SIDE-STOMACH, SHUSHING, SWINGING, SUCKING(5S'S) TERHADAP SKALA NYERI DAN DURASI TANGISAN PADA NEONATUS PASKA PROSEDUR PENGAMBILAN DARAH \\ (The Effect of Swaddling, Side-stomach, Shushing, Swinging, sucking (5S's) Toward Pain and Duration of Crying Neonates Post Blood Sampling Procedures)
}

\author{
Erni Setiyorini, Ning Arti Wulandari \\ STIKes Patria Husada Blitar \\ e-mail:nerserni@gmail.com
}

\begin{abstract}
Neonatal care at hospital involved many invasive procedures. The invasive procedures caused pain in neonates. The role of nurse is minimize the discomfort and pain for them. Negative effect when we let the pain in long time, there are immediately effect, short term effect and long term effect. 5S's technique is useful to make baby comfortable and soothing neonates.The purpose of this study was to analyze the application of 5S's technique to the pain and duration of crying neonates post blood sampling procedures. Method: Research design was experimental research with QuasiExperimental design post test only with control group. The sample consisted of 50 neonates, 25 nonates in control group and 25 neonates in the experimental group, with inclusion criteria: aterm neonates, normal apgar score. Sampling was done by purposive sampling. The data was analyze by T-test. Result: The results showed that $5 \mathrm{~s}$ 's technique had effect to pain with $p=0,000$ and duration of crying, with $p=0,011$. The research recommended for calming crying neonates and reduce pain after invasive procedures and it is expected the results of this study can be considered for standart operating procedures for calming neonates.
\end{abstract}

Keywords: technique 5S's, pain neonates, duration of crying, blood sampling procedures

Perawatan neonatal melibatkan banyak sekali prosedur invasif. Masing-masing memiliki keuntungan dan resiko spesifik. Seperti halnya prosedur pengambilan darah vena mempunyai keuntungan aliran darah yang baik dan menghindari hemolisis dari sampel darah. Namun prosedur tersebut juga memiliki resiko, misalkan memar, infeksi dan menimbulkan ketidaknyamanan pada bayi. Oleh sebab itu perawat perlu mempertimbangkan bagaimana meminimalkan ketidaknyamanan dan nyeri yang dirasakan oleh bayi. Tindakan invasif pengambilan darah vena yang didapatkan pada anak selama di rawat di rumah sakit menimbulkan dampak kecemasan, ketakutan dan ketidaknyamanan akibat nyeri yang dirasakan saat prosedur dilaksanakan
Pada zaman dahulu, bayi terutama yang baru lahir dianggap belum mampu memberikan respon nyeri. Hal ini disebabkan untuk dapat berespon terhadap nyeri diperlukan susunan saraf yang sempurna dan adanya pengalaman nyeri sebelumnya. Akan tetapi pandangan tersebut berubah, setelah ditemukan fakta bahwa sistem persarafan dan hormonal yang terlibat dalam proses penghantaran nyeri sudah terbentuk sempurna pada akhir trimester kedua kehamilan, sehingga bayi baru lahir cukup bulan sudah memiliki kemampuan menghantarkan nyeri dengan sempurna. Nyeri yang dialami bayi menimbulkan efek saat ini dan dimasa yang akan datang, secara spesifik digolongkan menjadi 3 pengaruh yaitu efek segera, efek jangka pendek dan efek jangka panjang. Efek segera menimbulkan rasa 
ketakutan, kegelisahan, gangguan waktu tidur dan bangun, penurunan jumlah konsumsi makanan, peningkatan jumlah produksi asam lambung; efek jangka pendek: gangguan imunologis (pertahanan tubuh), keterlambatan penyembuhan, gangguan pembentukan emosi, sedangkan efek jangka panjang: terbentuknya ingatan terhadap nyeri, retardasi pertumbuhan, perubahan dalam merespons nyeri. Sedangkan menurut Boyse (2007) nyeri dapat menyebabkan komplikasi medis, dan masalah dengan tidur, makan, dan regulasi diri. Hal ini juga dapat membuat anak-anak hipersensitif atau tidak sensitif terhadap rasa sakit di kemudian hari, atau menyebabkan rasa sakit kronis dan masalah lain di kemudian hari.

Comfort merupakan sebuah konsep yang mempunyai hubungan yang kuat dalam keperawatan. Comfort diartikan sebagai suatu keadaan yang dialami oleh penerima yang dapat didefinisikan sebagai suatu pengalaman yang immediate yang menjadi sebuah kekuatan melalui kebutuhan akan keringanan (relief), ketenangan (ease), and (transcedence) yang dapat terpenuhi dalam empat kontex pengalaman yang meliputi aspek fisik, psikospiritual, sosial dan lingkungan (Toomey and Aligood, 2006). Bayi mengkomunikasikan ketidaknyamanannya kepada kita dengan cara menangis (BabyCentre Medical Advisory Board, 2012). Menurut Kolkaba (2003) Teori Comfort dari ini menekankan pada beberapa konsep utama health care needs, comfort measures, enhanced comfort, intervening variable, health Seeking Behavior (HSBs) dan institusional integrity (Toomey and Aligood, 2006). Tindakan 5s's ini merupakan salah satu upaya yang dilakukan untuk meningkatkan kenyamanan pada bayi.

Penemuan konsep baru bahwa bayi baru

lahir sampai dengan usia 3 bulan tidak sepenuhnya siap di dunia, sehingga bayi yang menangis dapat dikondisikan seperti di dalam rahim ibu. Dr. Karp mengajarkan teknik untuk "mengkondisikan ulang seperti dalam kandungan" agar bayi tenang dan nyaman, dengan metode 5S's yang meliputi swaddling (membedong bayi), side posisi miring ke kiri/perut, shushing sound, swinging (gerakan berayun), sucking (mengisap). Tehnik tersebut dilakukan karena selama tiga bulan pertama setelah kelahirannya, bayi merindukan sensasi sensasi nyaman yang mereka alami selama berada dalam rahim. Berdasarkan hasil penelitian yang dilakukan oleh Dr.Harrington (2010) menyatakan bahwa sebagian besar bayi yang mendapatkan intervensi fisik 5S's berhenti menangis dengan 45 detik, sedangkan yang menerima larutan gula masih menangis 2 menit setelah prosedur invasif vaksinasi (Gupta, 2012). Pada bayi yang diambil darahnya membutuhkan pelayanaan untuk memenuhi kenyamanannya (health care needs). Oleh sebab itu peneliti ingin mengaplikasikan metode 5S's untuk menenangkan bayi setelah dilakukan prosedur pengambilan darah vena, dengan harapan nyeri yang dirasakan bayi berkurang/ hilang dan bayi dapat merasa tenang dan nyaman.

Berdasarkan uraian diatas, maka peneliti ingin membuktikan pengaruh teknik 5s's terhadap skala nyeri bayi, sehingga petugas kesehatan dapat memberikan intervensi segera terhadap pengalaman nyeri bayi dan akan berdampak positif yaitu menghindari efek negatif pengalaman nyeri jangka pendek maupun panjang. Tujuan penelitian tersebut adalah menganalisis pengaruh teknik 5S's terhadap nyeri dan durasi tangisan neonatus paska prosedur pengambilan darah vena.

\section{METODE PENELITIAN}

Pada penelitian ini menggunakan Quasy - Experimental Design dengan pendekatan Non Randomized Posttest Control Group Design. Populasi dalam penelitian ini adalah neonatus yang dirawat di ruang Edelweis RSUD Ngudi Waluyo Wlingi Blitar dengan prosedur pengambilan darah pada 14 April - 14 Juni 2014. Sampel dalam penelitian ini adalah neonatus yang memenuhi kriteria inklusi yaitu berusia $0-3$ bulan, aterm, tidak ada penyakit lain, apgar skor normal, menjalani prosedur invasif pengambilan darah vena. Teknik sampling yang digunakan adalah accidental sampling. Subjek penelitian sebanyak 50 neonatus yang terbagi menjadi 25 neonatus keompok perlakuan dan 25 neonatus keompok kontrol. Penelitian dilaksanakan di Ruang Edelweis RSUD Ngudi Waluyo Wlingi Blitar pada tanggal 14 April - 14 Juni 2014.

Variabel bebas penelitian ini adalah teknik swaddling, side-stomach, shushing, swinging, sucking (5S's) sedangkan variabel terikat penelitian ini adalah skala nyeri dan durasi tangisan. Untuk pengukuran skala nyeri menggunakan instrumen RIPS (Riley Infant Pain Scale).

Perlakuan yang diberikan adalah swaddling (membedong), side-stomach (memberikan posisi miring kearah lambung bayi), shushing (memberikan suara sssshhhhh di 
telinga bayi dengan intensitas sekeras tangisan bayi), swinging (mengayun-ayun bayi perlahanlahan) dan sucking (memberikan pacifier). Sedangkan pada kelompok kontrol dilakukan diberikan tindakan konvensional ruangan yaitu hanya dibedong.

Untuk analisis data, dilakukan uji normalitas dahulu pada data dengan menggunakan Saphiro-Wilk, setelah data diuji dengan hasil normal maka dilakukan uji T-test

\section{HASIL PENELITIAN}

Hasil penelitian meliputi karakteristik neonatus dan data khusus penelitian.

Tabel 1. Distribusi karakteristik Neonatus kelompok perlakuan di Ruang Edelweis RUD. Ngudi Waluyo Wlingi tanggal 14 April - 14 Juni 2014.

\begin{tabular}{|c|c|c|c|}
\hline No & Karakteristik & $\mathbf{f}$ & $(\%)$ \\
\hline \multirow[t]{3}{*}{1} & Jenis Kelamin & & \\
\hline & - Laki-laki & 11 & 44 \\
\hline & - Perempuan & 14 & 56 \\
\hline \multirow[t]{3}{*}{2} & Jenis Persalinan & & \\
\hline & - Normal & 7 & 28 \\
\hline & $-\quad \mathrm{SC}$ & 18 & 72 \\
\hline \multirow[t]{5}{*}{3} & Pengambilan Darah & & \\
\hline & $-\quad \operatorname{Ke} 1$ & 10 & 40 \\
\hline & $-\quad$ Ke 2 & 11 & 44 \\
\hline & $-\quad \operatorname{Ke} 3$ & 1 & 4 \\
\hline & - $\quad$ Ke 4 & 3 & 12 \\
\hline \multirow[t]{4}{*}{4} & Usia neonatus & & \\
\hline & - $0-3$ hari & 13 & 52 \\
\hline & - $4-7$ hari & 10 & 40 \\
\hline & $-8-14$ hari & 2 & 8 \\
\hline
\end{tabular}

Berdasarkan tabel 1 jenis kelamin neonatus kelompok perlakuan terbanyak adalah perempuan sebanyak 14 (56\%), jenis perssalinan terbanyak SC yaitu 18 (72\%), dan prosedur pengambilan darah yang terbanyak adalah pengambilan darah yang ke 2 yaitu 11 (44\%).
Tabel 2. Distribusi karakteristik Neonatus kelompok kontrol di Ruang Edelweis RUD. Ngudi Waluyo Wlingi tanggal 14 April - 14 Juni 2014.

\begin{tabular}{|c|c|c|c|}
\hline No & Karakteristik & $\mathbf{f}$ & $\%$ \\
\hline \multirow[t]{3}{*}{1} & Jenis Kelamin & & \\
\hline & - Laki-laki & 10 & 40 \\
\hline & - Perempuan & 15 & 60 \\
\hline \multirow[t]{3}{*}{2} & Jenis Persalinan & & \\
\hline & - Normal & 8 & 32 \\
\hline & $-\mathrm{SC}$ & 17 & 68 \\
\hline \multirow[t]{5}{*}{3} & Pengambilan Darah & & \\
\hline & - $\operatorname{Ke} 1$ & 9 & 36 \\
\hline & - $\quad \operatorname{Ke} 2$ & 10 & 40 \\
\hline & $-\quad \operatorname{Ke} 3$ & 5 & 20 \\
\hline & $-\quad \operatorname{Ke} 4$ & 1 & 4 \\
\hline \multirow[t]{4}{*}{4} & Usia neonatus & & \\
\hline & - $0-3$ hari & 13 & 52 \\
\hline & - $4-7$ hari & 10 & 40 \\
\hline & $-8-14$ hari & 2 & 8 \\
\hline
\end{tabular}

Berdasarkan tabel 2 jenis kelamin neonatus kelompok kontrol terbanyak adalah perempuan sebanyak $15(60 \%)$, jenis persalinan terbanyak SC yaitu 17 (68\%), dan prosedur pengambilan darah yang terbanyak adalah pengambilan darah yang ke 2 yaitu 10 (40\%)

\section{Intervensi Teknik 5s}

Tabel 3 Distribusi teknik (s) intervensi kelompok perlakuan di Ruang Edelweis RSUD. Ngudi Waluyo Wlingi tanggal 14 April - 14 Juni 2014.

\begin{tabular}{|c|c|c|}
\hline Teknik (s) & f & $\%$ \\
\hline $2 \mathrm{~s}$ & 4 & 16 \\
\hline $3 \mathrm{~s}$ & 3 & 12 \\
\hline$-4 s$ & 17 & 68 \\
\hline$-5 s$ & 1 & 4 \\
\hline
\end{tabular}

Teknik menenangkan neonatus setelah prosedur pengambilan darah yang terbanyak adalah teknik 4s yaitu sebanyak 17 (68\%).

\section{Hasil Uji Statistik}

Tabel 4 Hasil uji normalitas data dengan Shapiro-Wilk

\begin{tabular}{lccc}
\hline & \multicolumn{3}{c}{ Shapiro-Wilk } \\
\cline { 2 - 4 } & Statistic & df & Sig. \\
\hline Durasi Tangisan (detik) & .983 & 50 & .665 \\
Skala nyeri (Riley Infant Pain Scale) & .962 & 50 & .086 \\
\hline
\end{tabular}

Berdasarkan tabel 4 menunjukkan bahwa uji normalitas durasi tangisan sebesar 0,665 $(>0,05)$ yang berarti data berdistribusi normal. Demikian juga untuk skala nyeri menunjukkan nilai signifikansi $0,086(>0,05)$ yang berarti data skala nyeri berdistribusi normal. 


\section{Durasi Tangisan Neonatus Paska Tindakan Invasif Pengambilan Darah}

Tabel 5 Durasi tangisan neonatus kelompok perlakuan dan kelompok kontrol di Ruang Edelweis RSUD. Ngudi Waluyo Wlingi tanggal 14 April - 14 Juni 2014.

\begin{tabular}{cccccc}
\hline Kelompok & N & Mean & Min & Max & T-test \\
\hline Perlakuan & 25 & 20,30 & 10 & 40,56 & 0,011 \\
Kontrol & 25 & 28,34 & 3 & 50,12 & \\
\hline
\end{tabular}

Berdasarkan tabel 5 durasi tangisan rata - rata kelompok perlakuan lebih pendek dibandingkan dengan durasi tangisan rata - rata kelompok kontrol. Hasil uji statistik menunjukkan $\mathrm{p}=0,011$ yang berarti terdapat perbedaan durasi tangisan antara kelompok perlakuan dan kontrol.

Skala Nyeri dengan Menggunakan RIPS Paska tindakan Invasif Pengambilan Darah

Tabel 6 Skala nyeri neonatus kelompok perlakuan dan kelompok kontrol di Ruang Edelweis RSUD.

Ngudi Waluyo Wlingi tanggal 14 April - 14 Juni 2014.

\begin{tabular}{cccccc}
\hline Kelompok & N & Mean & Min & Max & T-test \\
\hline Perlakuan & 25 & 7,80 & 3 & 13 & 0,000 \\
Kontrol & 25 & 11,20 & 4 & 15 & \\
\hline
\end{tabular}

Berdasarkan tabel 6 skala nyeri dengan menggunakan RIPS, skala nyeri rata - rata pada kelompok perlakuan lebih rendah dibandingkan dengan kelompok kontrol. Hasil uji statistik menunjukkan $\mathrm{p}=0,000$, yang berarti terdapat perbedaan skala nyeri pada kelompok perlakuan dan kontrol.

\section{PEMBAHASAN}

\section{Karakteristik Neonatus}

Berdasarkan data karakteristik neonatus, sebagian besar neonatus pada kelompok perlakuan berjenis kelamin perempuan sebanyak 14 neonatus (56\%), lahir melalui operasi SC sebanyak 18 neonatus $(72 \%)$ dan prosedur pengambilan darah yang ke 2 sebanyak 11 neonatus (44\%), usia terbanyak 0 - 3 hari yaitu 13 neonatus $(52 \%)$. Anatomi dan fisiologi dasar nyeri telah muncul pada neonatus preterm. Neonatus yang dirawat di ruang perinatal sering mendapatkan pengalaman nyeri untuk periode waktu yang panjang. Neonatus memiliki peningkatan sensasi nyeri dan lebih sensitif terhadap nyeri dibandingkan anak - anak dan dewasa., dan rentan terhadap efek nyeri jangka panjang (Slater, dkk, 2006).

\section{Perbedaan skala nyeri kelompok perlakuan dan kelompok kontrol}

Rata-rata skala nyeri pada neonatus kelompok perlakuan adalah 7,80 dan pada kelompok kontrol 11,20. Hal ini menunjukkan bahwa skala nyeri yang dialami oleh kelompok perlakuan lebih rendah dibandingkan dengan pada kelompok kontrol. Hasil ini mendukung pendapat Harvey Karp bahwa intervensi 5S's dapat menurunkan skala nyeri akibat dari tindakan invasif. Pemberian intervensi 5S's didasarkan pada konsep bahwa 4 bulan setelah kelahiran, bayi belum siap sepenuhnya berada di luar rahim, bayi merindukan sensasi yang nyaman seperti di dalam rahim. Di dalam rahim ada simfoni sensasi, gerakan bergoyang yang konstan, bunyi mendesing yang konstan yang merupakan suara aliran darah melalui arteri dan menyentuh konstan terhadap dinding rahim. Melalui intervensi 5S's Karp menstimulasi rekondisi dalam rahim. Tindakan 5S's ini terdiri dari swaddling, yaitu membungkus bayi dengan membedong bayi dengan menggunakan kain katun yang lembut, hal ini memberikan ruang yang terbatas dan sentuhan yang terus menerus, sama seperti kondisi bayi dalam rahim dengan ruang yang terbatas. Membedong bayi dapat memusatkan perhatian bayi, menghentikan gerakan-gerakan memukul-mukul, mencegah rewel dan memberikan isyarat pada bayi bahwa sudah waktunya tidur. Tindakan yang kedua side/ stomach position, bayi baru lahir dapat menjadi panik dalam posisi telentang, karena adanya refleks moro yang mengejutkan bayi ketika mereka berpikir mereka jatuh. Cara yang cepat untuk membantu menenangkan bayi dalam kondisi stress adalah memposisikan bayi miring 
pada lengan/ pangkuan/ di atas bahu, posisi ini di dalam memori bayi sama seperti kondisi dalam rahim yaitu miring ke kiri atau kanan. Menurut Karp, posisi miring dan tengkurap tidak boleh diberikan pada saat bayi dalam kondisi tidur karena dapat memicu kondisi henti napas, terutama pada posisi tengkurap. Tindakan ketiga shushing, yaitu memberikan suara "ssshhhhhhh" di dekat telinga bayi sekeras frekuensi tangisan. Sura ini meniru suara aliran darah ibu ketika bayi masih di dalam rahim. Pengujian yang dilakukan pada tahun 1970-an menegaskan bahwa di dalam rahim, bayi terpapar dengan bunyi kebisingan 80-90 desibel. Beberapa bunyi lain dapat menyerupai "ssshhhhh" yaitu bunyi radio statis, bunyi vacuum cleaner atau mesin cuci, shower dan kipas. Tindakan keempat adalah swinging, yaitu tindakan mengayun ayunkan bayi pelan - pelan pada lengan, tidak terlalu keras dalam menggoyang bayi. Gerakan ayunan kecil agar kepala bayi tetap sejalan dengan tubuhnya, gerakan tidak lebih dari $1-2$ inchi dari sisi ke sisi. Selama dalam rahim, bayi terbiasa terus - menerus bergoyang - goyang dalam cairan ketuban. Replikasi dari ayunan ini adalah cara cepat untuk membantu menenangkan bayi baru lahir. Tindakan lain yang menyerupai swinging adalah goncangan dari kereta, ayunan di tempat tidur gantung, ayunan bayi dan goncangan mobil yang sedang melaju. Tindakan yang kelima adalah sucking/ menghisap. Intervensi nyeri non farmakologis dengan sucking telah terbukti bermanfaat dalam pengelolaan nyeri ringan - sedang pada neonatus. Termasuk didalamnya adalah sucking non nutritif, ASI, MPASI. Pemberian ASI dapat efektif karena diikuti dengan kontak kulit. Metode pemberian ASI dapat merangsang aktivasi neuropeptida, seperti cholecytokinin (CCK). CCK merupakan zat modulasi opioid yang mendukung adaptasi stressor dan dapat mencapai efek analgesik melalui potensiasi aktifitas opioid. Selain itu ASI mengandung gula yang memberikan efek analgesia. Bila bayi terbiasa dengan dot/ pacifier, tindakan sucking dapat diberikan. Berdasarkan teori, pada usia 5 bulan kehamilan, refleks menghisap pada bayi berkembang. Pada saat tangan berada disekitar mulut, bayi refleks menghisap jari (ACOG, 2014). Pemberian tindakan sucking akan mengembalikan kenyamanan bayi ketika berada dalam kandungan.

Intervensi tindakan dengan 5S's merupakan salah satu dari penatalaksanaan nyeri non farmakologik yaitu metode distraksi.
Distraksi dapat menurunkan persepsi nyeri dengan menstimulasi sistem kontrol desenden sehingga stimulasi nyeri yang ditransmisikan ke otak lebih sedikit. Efektifitas teknik distraksi tergantung pada kemampuan individu dalam menerima dan membangkitkan stimuli sensoris selain dari rangsang nyeri yang diterima. Penurunan nyeri secara umum dapat optimal dengan melibatkan partisipasi aktif dari individu, keterlibatan modalitas sensoris yang digunakan dan minat individu terhadap stimuli. Stimulasi dengan melibatkan beberapa indera seperti penglihatan, pendengaran, sentuhan lebih efektif dalam menurunkan nyeri dibandingkan dengan hanya melibatkan satu indera saja. Intervensi 5S's yaitu Swaddling, Side, Shushing, Swinging, Sucking melibatkan beberapa indera sehingga lebih efektif dalam menurunkan nyeri.

Menurut penelitian Harrington (2012) intervensi 5s's dapat menurunkan skala nyeri pada neonatus paska tindakan imunisasi pada imunisasi rutin bayi usia $2-4$ bulan.

Beberapa riset menunjukkan bahwa kegagalan dalam mengatasi nyeri pada neonatus akan menyebabkan perubahan permanen pada proses di otak dan perilaku maladaptif selanjutnya (Anand, 2000).

Nyeri yang dialami oleh neonatus memiliki efek yang merugikan terhadap kemampuan neonatus berikutnya dalam belajar dan mengingat informasi baru. Stress akibat nyeri yang berkepanjangan juga berakibat penurunan ireversibilitas dendrite di hippocampus. Nyeri yang berulang - ulang atau stress lebih lanjut akan mempengaruhi apoptosis.

\section{Perbedaan durasi tangisan kelompok perlakuan dan kontrol}

Hasil penelitian menunjukkan adanya perbedaan yang signifikan durasi tangisan neonatus kelompok perlakuan dan kelompok kontrol dengan $p=0,011$. Sesuai dengan teori bahwa neonatus dan bayi memiliki keunikan dalam perilaku awal kehidupan untuk bertahan hidup, kesehatan dan perkembangan. Secara umum, menangis adalah tanda biologis, kewaspadaan pada perawat terhadap kebutuhan dan keinginan bayi dan memotivasi pendengar untuk merespon tangisan. Bagi bayi menangis merupakan cara untuk mengkomunikasikan pesan. Tangisan pada neonatus merupakan reaksi terhadap stimuli eksternal maupun internal. Bradelton, 1962 dalam McCarrol dan Fariz tahun 2010 menyatakan bahwa tangisan merupakan respon terhadap kebutuhan 
diantaranya perubahan suhu, lapar dan nyeri atau ketidaknyamanan.

Dengan durasi tangisan yang pendek setelah diberikan intervensi 5S's, hal ini mendukung perkembangan psikososial anak yaitu fase pembentukan rasa percaya dan tidak percaya. Menurut Erikson dua tindakan pengasuh/ orang tua dapat mendukung perkembangan ini yaitu pemberian makan dan respon terhadap tangisan bayi. Mengabaikan tangisan bayi dapat menyebabkan gangguan perkembangan psikososial selanjutnya yaitu rasa curiga, takut dan tidak percaya (Wong, 2009).

Beberapa neonatus kelompok kontrol memiliki durasi tangisan lebih pendek dari kelompok perlakuan. Pada kelompok kontrol, bayi hanya dibedong, yaitu salah 1 tindakan dari 5S's (Swaddling), tindakan ini juga salah satu tindakan rekondisi dalam rahim. Faktor lain yang mendukung yaitu bayi dalam kondisi kenyang, sehingga mudah ditenangkan. Beberapa neonatus kelompok perlakuan memiliki durasi tangisan yang lebih panjang dari kelompok kontrol, hal ini dapat disebabkan oleh karena adanya faktor lain, yaitu ketidaknyamanan lain yang dirasakan bayi, diantaranya karena lapar, mengantuk dan kelelahan.

\section{SIMPULAN DAN SARAN Simpulan}

Simpulan dalam penelitian ini adalah adanya pengaruh tindakan 5 S's terhadap skala nyeri neonatus yang ditunjukkan dengan uji statistik t-test dengan $\mathrm{p}=0,000$; adanya pengaruh tindakan 5S's terhadap durasi tangisan neonatus yang ditunjukkan denganuji statistik t-test dengan $\mathrm{p}=0,011$.

Saran

Saran yang dapat diberikan dari hasil penelitian ini adalah sebagai bagi institusi pendidikan, diharapkan materi teknik 5S's ini dapat ditambahkan, khususnya pada mata kuliah sistem reproduksi 2 tentang penatalaksanaan bayi baru lahir; Bagi rumah sakit, diharapkan hasil penelitian ini dapat menjadi bahan pertimbangan dalam membuat SOP (Standart Operatinal Procedures) dalam menenangkan neonatus dan dapat mensosialisasikan kepada ibu, bahwa tindakan 5S's sangat bermanfaat bagi neonatus dan menjelaskan efek negative dari nyeri dan tangisan yang tidak segara ditangani.

\section{DAFTAR RUJUKAN}

Babycentre (2012). Seven Reasons Baby Cry and how to soothe Them. Dibuka tanggal 14 April 2013. Dari http://www.babycentre.co.uk/a536698/sev en-reasons-babies-cry-and-how-to-soothethem-

Boyse, Keyla. (2007). Pain and Your Infant: Medical Procedures, Circumcision and Teething.

http://www.med.umich.edu/yourchild/topi cs/paininf.htm dibuka tanggal 20 Nopember 2013.

Gupta,S.(2012).The 5S's: Easing Baby Pain After Vaccine Shots. Dibuka tanggal 14 April 2013.2 Dari http://thechart.blogs.cnn.com/2012/04/16/t he-5-ss-easing-baby-pain-after-vaccineshots/.

Karp Harvey.( 2002). Bayi paling bahagia sedunia. Gramedia. Jakarta

Stright, B.(2001). Keperawatan Ibu Bayi Baru Lahir. Edisi 3 Alih Bahasa Maria A. Wijayarini. Jakarta: EGC.

Tommey and Alligood. (2006). Nursing Theorist and Their Work. Philadelphia USA: Mosby.

Wong,D.L, Hockenberry M, Wilson,D, Winkelstein,M.L, \& Schwartz, P.(2002). Buku Ajar Keperawatan Pediatrik Wong, Ed 6, Vol I.Alih Bahasa Agus Sutarna. Jakarta:EGC.

John.W. Harrington, MDa,b, Stacey Logan, MDa, Courtney Harwell, MDa, Jessica Gardner, MDa, Jessica Swingle, BSa, Erin McGuire, MSa, and Rosemarie Santos, MDa.(2012).Effective Analgesia Using Physical Interventions for Infant Immunizations. American Academy of Pediatrics. http://pediatrics.aappublications.org/conte nt/early/2012/04/11/peds.2011-1607. abstract

Anand K. (2000).Pain, plasticity, and premature birth: A prescription for permanent suffering? Nature Medicine; 6:971-73.

Anand K, and Hickey P. Pain and its effects in the human neonate and fetus. New England Journal of Medicine 1987; 317:1321-29.

Anand K, and Scalzo F. (2000).Can adverse neonatal experiences alter brain development and subsequent behavior? Biology of the Neonate; 77:69-82 
Slater, R, Cantarella, A, Gallella, S, et al. Cortical pain responses in human infants. J Neurosci 2006; 26:3662.

The American Congress of Obstetricians and Gynecologist (ACOG).(2011). How Your Baby Grows During Pregnancy. http://www.acog.org/Patients/FAQs/HowYour-Baby-Grows-During-Pregnancy dibuka tanggal 28 Agustus 2014. 